\title{
Awareness of carcinoma cervix in nursing personnel of a tertiary care institute, Mumbai, India
}

\author{
Pooja K. Bandekar*, Prashant B. Kale
}

Department of Obstetrics and Gynecology, Seth G.S. Medical College and Nowrosjee Wadia Maternity Hospital, Mumbai, Maharashtra, India

Received: 03 December 2017

Accepted: 14 December 2017

*Correspondence:

Dr. Pooja K. Bandekar,

E-mail: pujuobgy@gmail.com

Copyright: () the author(s), publisher and licensee Medip Academy. This is an open-access article distributed under the terms of the Creative Commons Attribution Non-Commercial License, which permits unrestricted non-commercial use, distribution, and reproduction in any medium, provided the original work is properly cited.

\section{ABSTRACT}

Background: Carcinoma cervix is the second most common cancer of women all over the world and commonest cancer among Indian women. Awareness about cervical cancer and its prevention low amongst Indian women. The Pap test is a simple cost-effective technique for screening to help early diagnosis of cervical cancer. Nursing staff should be made aware of cervical cancer, so that they can spread the knowledge to the general public. Objectives of present study were to assess the knowledge level regarding symptoms, risk factors, prevention and screening of cervical carcinoma among nursing staff and to find out the behaviour of respondents regarding prevention and screening of cervical carcinoma

Methods: A cross-sectional interview-based survey regarding knowledge of cervical carcinoma was conducted among the nursing staff of a tertiary care institutes of Mumbai.A structured questionnaire with multiple choices was used as a tool for data collection. Provision for open-ended responses was also made in the questionnaire. 100 nurses participated in the current study. Data was entered in Microsoft Excel. SPSS statistical software was used to generate statistical parameters like proportion, mean, standard deviation, etc. The test of significance used was the $\mathrm{Z}$ test and a $P$ value of $<0.05$ was considered as the level of significance.

Results: We lack an organized opportunistic screening program for cervical cancer in India. Data indicates a slow, but steady, decline in the incidence of cervical cancer. However, the rates are still too high, particularly in the rural areas. It is extremely essential to screen eligible women when they come to health units for other services. Studies have shown it is possible to train nurses to screen for cervical cancer. Attitudes that screening is to be done by doctors or gynaecologists only needs to change. The survey revealed that the hospital played a limited role as a source of information on Pap smear. This calls for a re-orientation of nurses, paramedicals and health workers and a need for introduction of simpler cervical cancer screening methods such as visual inspections that are more sustainable Conclusions: Awareness about cervical cancer has to be improved. Education of the nursing personel will strongly contribute to strengthen cervical cancer screening programs. Nursing staff can and should educate the masses to help increase health awareness in women.

Keywords: Cervical cancer, Knowledge, Nursing staff, Pap test, Screening

\section{INTRODUCTION}

International Agency for Research on Cancer (IARC) states that India has the highest number of cervical cancer cases in the world. Estimated 1,32,000 new cases and
74,000 deaths occur every year due to cervical cancer in India. ${ }^{1}$ Sexually transmitted infection with human papilloma virus (HPV) is a precursor to the development of carcinoma cervix. Its prevalence increases due to multiple sexual partners and poor genital hygiene. There 
are $100 \mathrm{HPV}$ types of which 18 are high-risk for cervical cancer, and the rest are low-risk. ${ }^{2}$ Cervarix ${ }^{\circledR}$ by Glaxo SmithKline (GSK) is a bivalent vaccine that protects against HPV strains 16 and 18, and Gardasil® by Merck is a quadrivalent vaccine that protects against HPV strains 16, 18, 6 and 11. These two types of vaccine are available with private health care providers though there is no provision for HPV vaccine at the institute where the study has been carried out. HPV types 16 and 18 accounts for almost $70 \%$ of all cervical cancer cases in India. ${ }^{3}$ The Programme for Appropriate Technology in Health (PATH), a USA-based not for profit nongovernmental organization (NGO), has been working on coverage, acceptability, feasibility and costs of the vaccines in two Indian states, Gujarat and Andhra Pradesh, and it is funded by the Bill \& Melinda Gates Foundation. ${ }^{4}$ The study was suspended in April 2010 by the Government of India vide concerns about safety. PATH and the Indian government are investigating whether to implement a HPV vaccination program. ${ }^{5}$

Of all the female genital tract cancers, cervical cancer is a deadly disease once in the invasive stages, nevertheless, it is the only preventable cancer, if detected at its early stages. Population screening with Pap smear is an important secondary preventive measure for cervical cancer helping in a high-cure rate amongst patients. The facilities to do a Pap smear are available in the institute where the study has been carried out.

A recent qualitative study reported a low level of awareness about HPV and cervical cancer amongst the general population and even the health service providers of particular four developing countries (India, Peru, Uganda and Vietnam). ${ }^{6}$ Very similar results, were found in several studies conducted in many other countries all over the world. ${ }^{7-11}$

Nurses can provide information to all the patients they serve in day-to-day practice. They play a key role in health promotion and disease prevention. They are an ideal to provide health education to young girls and women. Hence the nursing staff should be aware about cervical cancer, sources of knowledge of cervical cancer and its prevention. The present study was to assess the knowledge of the nursing staff of a tertiary health institute.

\section{METHODS}

This is cross-sectional study carried out among the nursing staff of a tertiary health institute in mumbai. The duration for the study was from March to August 2008, over a period of six months. A total of 675 nursing staff were enrolled in this study. $15 \%$ of staff were randomly selected. Practically a total of 100 nurses were selected for the study. Verbal-informed consent was sought from the subjects. A structured questionnaire was designed. There also was a provision for open-ended responses in the format. The selected nurses were interviewed for the socio-demographic profile of the respondents, their knowledge about symptoms, risk factors and prevention, their attitude and awareness of Pap smear for screening for carcinoma cervix.

\section{Statistical analysis}

Data entry was done, and SPSS statistical software was used to generate statistical parameters like proportion, mean, standard deviation, etc. $\mathrm{Z}$ test was used as a test of significance, and $\mathrm{P}$ value of $<0.05$ was considered as level of significance.

\section{RESULTS}

Out of 100 staff nurses, $60 \%$ belonged to the age group of 41-50 years. The mean age of the study population was 46 years. The majority of respondents $(90 \%)$ were married (Table 1).

Table 1: Social and -demographic profile of study population.

\begin{tabular}{|lcc|}
\hline Variable & Number & Percentage \\
\hline Age & & \\
\hline $21-30$ & 4 & 4 \\
\hline $31-40$ & 16 & 16 \\
\hline $41-50$ & 60 & 60 \\
\hline $51-60$ & 20 & 20 \\
\hline Marital status & & \\
\hline Married & 90 & 90 \\
\hline Unmarried & 10 & 10 \\
\hline Widow & 0 & 0 \\
\hline Socio economic class (Modified Prasad classification) \\
\hline Class 1 & 90 & 90 \\
\hline Class 2 & 10 & 10 \\
\hline Total & 100 & 100 \\
\hline
\end{tabular}

$69 \%$ of respondents had some knowledge of cervical carcinoma. Almost $90 \%$ of the study population belong to class 1 as per modified Prasad Classification (Table 1).

As per information regarding knowledge of the symptoms of cervical cancer, only 65 (94.2\%) respondents stated vaginal discharge as one of the symptoms.

The percentages of respondents who mentioned menstrual abnormality and pain as symptoms were 86.9 and 66.6 , respectively. 40 (71.1\%) of the staff nurses believed that early marriage was an important risk factors were as $51(73 \%)$ felt that early pregnancy was an important risk factors and $43(62.3 \%)$ were of the opinion that repeated pregnancy was an important risk factors. Only eight $(11.5 \%)$ respondents were aware of multiple sexual partners as one of the risk factors of cervical carcinoma. 
Out of 69 respondents who had some knowledge regarding cervical carcinoma, 61 (88.4\%) had knowledge regarding Pap test as one of the preventive measures (Table 2). Out of 62 staff nurses who knew about Pap test, only five ( $8 \%$ ) had undergone Pap test (Table 3 ).

Table 2: Knowledge about various aspects of carcinoma cervix.

\begin{tabular}{|c|c|c|c|c|}
\hline Aspects & Frequency & $\%$ & $\begin{array}{l}\mathrm{Z} \\
\text { value }\end{array}$ & $\begin{array}{l}P \\
\text { value }\end{array}$ \\
\hline \multicolumn{5}{|l|}{ Symptoms } \\
\hline $\begin{array}{l}\text { Menstrual } \\
\text { abnormality }\end{array}$ & 60 & 86.5 & 1.4 & $>0.05$ \\
\hline $\begin{array}{l}\text { Vaginal } \\
\text { discharge }\end{array}$ & 65 & 94.2 & 1 & - \\
\hline Pain & 46 & 66.6 & 4.3 & $<0.05$ \\
\hline Others & 28 & 40.5 & 8.6 & $<0.05$ \\
\hline \multicolumn{5}{|l|}{ Risk factors } \\
\hline Early marriage & 49 & 71.1 & 0.3 & $>0.05$ \\
\hline Early pregnancy & 51 & 73.9 & 1 & - \\
\hline $\begin{array}{l}\text { Repeated } \\
\text { pregnancy }\end{array}$ & 43 & 62.3 & 1.4 & $>0.05$ \\
\hline $\begin{array}{l}\text { Oral } \\
\text { contraceptives }\end{array}$ & 12 & 17.3 & 6.9 & $<0.05$ \\
\hline $\begin{array}{l}\text { Multiple sexual } \\
\text { partners }\end{array}$ & 8 & 11.5 & 6.5 & $<0.05$ \\
\hline \multicolumn{5}{|c|}{ Preventive measures } \\
\hline $\begin{array}{l}\text { Good genital } \\
\text { hygiene }\end{array}$ & 57 & 82.6 & 5.9 & $<0.05$ \\
\hline Use of condom & 59 & 85.5 & 5.7 & $<0.05$ \\
\hline PAP Test & 61 & 88.4 & 1 & - \\
\hline Total & 69 & 100 & & \\
\hline
\end{tabular}

Table 3: Knowledge regarding PAP smear.

\begin{tabular}{|llll|}
\hline $\begin{array}{l}\text { Knowledge } \\
\text { about PAP }\end{array}$ & PAP Done & \multicolumn{1}{c|}{ Total } \\
\hline Present & $5(8.1)$ & $57(91.9)$ & $62(100)$ \\
\hline Absent & $0(0)$ & $38(100)$ & $38(100)$ \\
\hline Total & $5(5 \%)$ & $95(95)$ & $100(100)$ \\
\hline
\end{tabular}

Figure in parenthesis include row-wise percentages

\section{DISCUSSION}

This study was conducted among staff nurses to evaluate their knowledge regarding carcinoma cervix. $69 \%$ of staff nurses had some knowledge related to cancer of the cervix. In the present study, 86.9 and $94.2 \%$ mentioned menstrual abnormality and abnormal vaginal discharge, respectively, as symptoms of cervical cancer, while in a study by Nganwai et al, this proportion was77.7 and $92.4 \%$ respectively. ${ }^{7}$ This was $80.6 \%$ in a study by Anya et al. ${ }^{8}$

In present study, only $11.5 \%$ knew of multiple sexual partners as one of the risk factors. In a study of Ali et al,
$45 \%$ and in a study carried out by McCarey et al, $41 \%$ of the nurses knew this. ${ }^{9,10}$ In the present study, $73.9 \%$ mentioned early age at pregnancy as one of the risk factors for cervical cancer. In the study by Nganwai et al 81.8 and $85.6 \%$ of respondents knew these as risk factors for cervical cancer. ${ }^{7}$

In the present study, knowledge regarding Pap test was present in $88.4 \%$ of respondents. Similar findings $(83 \%)$ were documented in a study carried out by Mutyaba et al. ${ }^{11}$ In a study by Ali et al, only $75 \%$ knew the same. ${ }^{9}$

In the present study, only $5(5 \%)$ respondents underwent Pap test. The same result $(5.5 \%)$ was there in a study by Udigwe. ${ }^{12}$ However, in a study carried out by Nganwai et al, 56.4\% underwent Pap smears every year. ${ }^{7}$

We lack an organized opportunistic screening program for cervical cancer in India. ${ }^{13}$ Data indicates a slow, but steady, decline in the incidence of cervical cancer. However, the rates are still too high, particularly in the rural areas. ${ }^{13}$ It is extremely essential to screen eligible women when they come to health units for other services. Studies have shown it is possible to train nurses to screen for cervical cancer. ${ }^{14}$ Attitudes that screening is to be done by doctors or gynaecologists only needs to change. The survey revealed that the hospital played a limited role as a source of information on Pap smear. This calls for a re-orientation of nurses, paramedicals and health workers and a need for introduction of simpler cervical cancer screening methods such as visual inspections that are more sustainable. ${ }^{15}$

\section{CONCLUSION}

Awareness about cervical cancer has to be improved. Education of the nursing personel will strongly contribute to strengthen cervical cancer screening programs. Nursing staff can and should educate the masses to help increase health awareness in women.

Funding: No funding sources

Conflict of interest: None declared

Ethical approval: Not required

\section{REFERENCES}

1. Laikangbam $P$, Sengupta $S$, Bhattacharya $P$, Duttagupta C, Dhabali Singh T, Verma Y, et al. A comparative profile of the prevalence and age distribution of human papillomavirus type 16/18 infections among three states of India with focus on northeast India. Int J Gynecol Cancer. 2007 Jan 1;17(1):107-17.

2. World Health Organization International Agency for Research on Cancer. International Agency for Research on Cancer. IARC Monographs on the evaluation of carcinogenic risks to humans. Human Papillomavirus (Lyon: International Agency for Research on Cancer). 2007;90. 
3. Bharadwaj M, Hussain S, Nasare V, Das BC HPV and HPV vaccination: issues in developing countries Indian J Med Res. 2009;130:327-33.

4. PATH and National AIDS Research Institute. Shaping a Strategy to Introduce HPV Vaccines in India: Results from the HPV Vaccines. Evidence for Impact Project (Seattle, WA: PATH). Available at http://screening.iarc.fr/doc/PATH_FRTS_India.pdf

5. Mattheij I, Pollock AM, Brhlikova P. Do cervical cancer data justify HPV vaccination in India? Epidemiological data sources and comprehensiveness. J R Soc Med. 2012;105:250262.

6. Bingham A, Drake JK, LaMontagne DS. Sociocultural issues in the introduction of human papillomavirus vaccine in low-resource settings Arch Pediatr Adolesc Med. 2009;163:455-61.

7. Nganwai P, Truadpon P, Inpa C, Sangpetngam B, Mekjarasnapa M, Apirakarn $\mathrm{M}$ et al. Knowledge, attitudes and practices vis-a-vis cervical cancer among registered nurses at the Faculty of Medicine, Khon Kaen University, Thailand. Asian Pac J Cancer Prev. 2008;9:15-18.

8. Anya SE, Oshi DC, Nwosu SO, Anya AE. Knowledge, attitude and practice of female health professionals regarding cervical cancer and Pap smear Niger J Med. 2005;14(3):283-6.

9. Ali SF, Ayub S, Manzoor NF, Azim S, Afif M, Akhtar $\mathrm{N}$ et al. Knowledge and awareness about cervical cancer and its prevention amongst interns and nursing staff in Tertiary Care Hospitals in Karachi, Pakistan. PloS One. 2010 Jun 10;5(6):e11059.
10. McCarey C, Pirek D, Tebeu PM, Boulvain M, Doh AS, Petignat P. Awareness of HPV and cervical cancer prevention among Cameroonian healthcare workers. BMC Women's Health. 2011 Oct $18 ; 11(1): 45$.

11. Mutyaba T, Mmiro FA, Weiderpass E. Knowledge, attitudes and practices on cervical cancer screening among the medical workers of Mulago Hospital, Uganda. BMC Medical Education. 2006 Dec $1 ; 6(1): 13$.

12. Udigwe GO. Knowledge, attitude and practice of cervical cancer screening (pap smear) among female nurses in Nnewi, South Eastern Nigeria Niger J Clin Pract. 2006;9(1):40-3.

13. Sankaranarayanan R, Budukh AM, Rajkumar R. Effective screening programmes for cervical cancer in low- and middle-income developing countries. Bull World Health Organ. 2001;79:954-62.

14. Chirenje ZM, Chipato T, Kasule J, Rusakaniko S. Visual inspection of the cervix as a primary means of cervical cancer screening: results of a pilot study. Cent Afr J Med. 1999;45:30-3.

15. Cronje HS, Parham GP, Cooreman BF, de Beer A, Divall P, Bam RH. A comparison of four screening methods for cervical neoplasia in a developing country. Am J Obstet Gynecol. 2003;188:395-400.

Cite this article as: Bandekar PK, Kale PB. Awareness of carcinoma cervix in nursing personnel of a tertiary care institute, Mumbai, India. Int J Reprod Contracept Obstet Gynecol 2018;7:128-31. 